\title{
Wear Evaluation of WC Inserts Coated with TiN/TiAIN Multinanolayers
}

L. H. Moreno

lhmoreno@sena.edu.co

CDT - ASTIN SENA

Hard Coatings Laboratory

Cali, Colombia

\section{J. C. Ciacedo}

jcesarca@calima.univalle.edu.co

Universidad del Valle

Department of Physics

Cali, Colombia

\section{F. Martinez}

fmartinez@mecanica.cujae.edu.cu Inst. Sup. Politécnico José Antonio Echeverría Dpto. de Tecnología Fac. Mecánica

La Habana, Cuba

$$
\begin{array}{r}
\text { G. Bejarano } \\
\text { gbejarano@udea.edu.co } \\
\text { Universidad de Antioquia } \\
\text { Corrosion and Protection Group, Engineering and } \\
\text { Composite Materials Science Group } \\
\text { Medellin, Colombia } \\
\text { T. S. Battaille } \\
\text { Inst. Sup. Politécnico José Antonio Echeverría } \\
\text { Dpto. de Tecnología Fac. Mecánica } \\
\text { La Habana, Cuba } \\
\text { P. Prieto@calima.univalle.edu.co } \\
\text { Universidad del Valle } \\
\text { Paleto } \\
\text { Cali, Colombia }
\end{array}
$$

\section{P. Prieto}

TiN/TiAlN multilayers were deposited by radio frequency, r.f., reactive magnetron sputtering by using titanium and aluminum targets with $10 \mathrm{~cm}$ diameter and $99.99 \%$ purity in an argon/nitrogen atmosphere, applying a substrate temperature of $300{ }^{\circ} \mathrm{C} . \mathrm{WC}$ inserts were used as substrates to improve the mechanical and tribological properties of TiN/TiAlN multilayered coatings compared to other types of coatings like TiAlN monolayers and to manage greater efficiency of these coatings in different industrial applications, such as machining, and extrusion. Their physical, mechanical, and tribological characteristics were investigated, including cutting tests with AISI 4340 hardened steel (50 HRC) to assess wear as a function of the period and number of bilayers. A comparison of the properties of TiCN-Al2O3-TiN monolayers coatings and the [TiN/TiAlN]300 multilayers with individual layer thicknesses of $10 \mathrm{~nm}$ revealed a decrease of flank wear (around 33\%) for [TiN/TiAlN]300 multilayers and a reduction of flank wear (around 13\%) for coatings with 300 layers when is compared with [TiN/TiAlN]200 coatings. They also showed better machining properties onto hardened AISI 4340 steel pieces, when compared to uncoated WC inserts. These results open the possibility of using [TiN/TiAlN] multilayers as new coatings for tool machining with excellent industrial performance.

Keywords: hard coatings, multinanolayers, tool wear, cutting tools

\section{Introduction}

Multilayered structures have been studied extensively and used for many years in coating technology to improve performance in industrial use. Among these multilayered structures, there are antiwear coatings for applications in machining processes (Braic et al., 2003) (Musil, 2000). High hardness, good adhesion to the substrate, high chemical stability, and low-friction coefficient make these multilayered structures (Holleck, 1986) good options to diminish wear. In recent work, the high hardness and toughness of the nanometric layers in multilayered coatings have shown additional advantages as protective coatings against corrosion and wear of tools and machined parts. Some of these multilayered systems are denominated superlattices, e.g., Zr/ZrN, ZrN/TiN, and TiN/TiAlN, which evidence hardness above $30 \mathrm{GPa}$ and greater efficiency in high-speed machining (Holleck, 1986).

TiN and TiAlN films are known for their important physical characteristics which depend mainly on deposition parameters like:

Paper accepted August, 2009. Technical Editor: Anselmo Eduardo Diniz working pressure, partial nitrogen pressure, substrate temperature, target-to-substrate distance, power applied to the target, and deposition rate (Holleck, 1986). When steel is machined with WC inserts, different wear mechanisms become apparent, such as: abrasion, adhesion, oxidation, and diffusion. These act simultaneously, depending mainly on temperature (Usui, 1998). Determining which of these mechanisms is predominant is a complex task; however, Oxley® (Guo and Janowski, 2002) (Oxley, 1989) offers some criteria related to the influence of cutting speed. This parameter is the fundamental reason for the increase in temperature and wear in the cutting zone. Abrasion is a predominant phenomenon at low cutting speeds, adhesion is noted at medium speeds, and diffusion occurs at high cutting speeds. The values for the speed at which the maximum wear values occur will depend on different factors, such as the combination of tool, work piece materials, contact time between them, and the geometry of the tool, among others (Guo and Janowski, 2002) (Oxley, 1989). One of the most important phenomena during the machining process is the generation of heat in the cutting zone. Most researchers such as Shaw (1984) and Komanduri et al. (2001) agree that most of the energy spent in the cutting process is converted into heat. All this 
heat is distributed onto the tool, the piece, the chips, and a small portion onto the environment. The heat on the chips and on the piece may facilitate the cutting process, but heat on the tool will produce a decrease in its useful life; thereby, affecting the cutting process (Shaw, 1984) (Komanduri et al., 2001). In this work, titanium nitride (TiN) and titanium aluminum nitride (TiAlN) multilayered films were deposited and characterized via reactive r.f. magnetron sputtering, and the process parameters were optimized to prepare TiN/TiAlN multilayers to study the effect on physical properties like high hardness, high wear resistance, and good adhesion to the substrate. The main purpose of this work is the evaluation of the influence on the mechanical properties of the number of $[\mathrm{TiN} / \mathrm{TiAlN}]_{200}$ and $[\mathrm{TiN} / \mathrm{TiAlN}]_{300}$ heterostructures as compared to properties of a $\mathrm{TiCN}-\mathrm{Al}_{2} \mathrm{O}_{3}$-TiN nano-structured monolayer and inserts with polycrystalline cubic boron nitride (PCBN) substrates and different types of coatings that yielded good durability performance.

\section{Nomenclature}

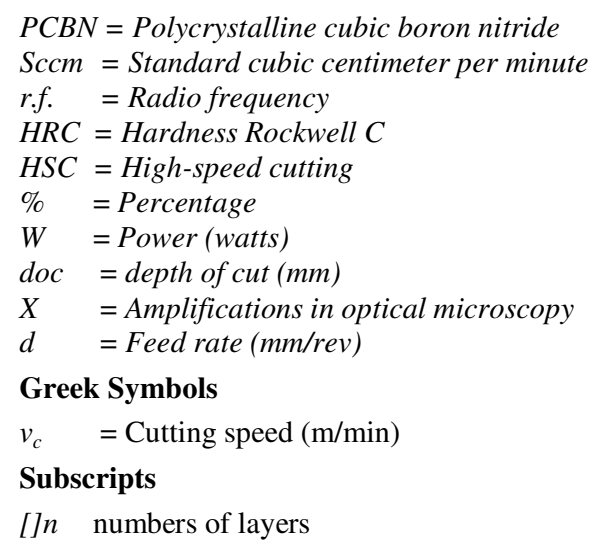

\section{Experimental Details}

TiN/TiAlN heterostructures were grown by using the r.f. magnetron sputtering $(13.56 \mathrm{MHz})$ technique at the Center for Technological Development, CDT-ASTIN, SENA Regional Valle, which is part of the Center of Excellence for Novel Materials CENM in Colombia (www.cenm.org) (see Fig. 1). TiN/TiAlN films were also deposited onto WC insert substrates. The sputter target was pure titanium $(99.99 \%)$ and aluminum $(99.95 \%)$. The sputtering gas used was high-purity argon (99.999\%). The base pressure was under $6 \times 10-5$ mbar. The composition of the gas mixture was controlled by flow meters and the argon flux $(50 \mathrm{sccm})$ was fixed and corresponds to $93 \%$ of the total argon gas. The $\mathrm{N}_{2}(99.99 \%$ purity) flux ranged from $7 \%$ of the total flux used as gas, corresponding to $(3.7 \mathrm{sccm})$. The deposition chamber pressure during film deposition was $6 \times 10^{-3}$ mbar. The r.f. power was always $300 \mathrm{~W}$ for $\mathrm{Al}$ and $400 \mathrm{~W}$ for Ti. The substrate holder was kept at $300{ }^{\circ} \mathrm{C}$ and a negative r.f. bias was applied to the substrate around $-100 \mathrm{~V}$. The deposition parameters used are shown in Table 1. Prior to TiN/TiAlN deposition, the targets were cleaned by argon glow discharge and then a pure thin Ti layer, with thickness of $5 \mathrm{~nm}$, was first deposited to improve TiN adhesion to the substrate. Special care was taken to generate the multinanolayer effect of positioning the Al target discharge. During deposition in $\mathrm{N}_{2}$ atmosphere, the fluxes of the reactive gases were fixed. These discharges were periodically interrupted and, then, the Ti target was kept constant under argon glow discharge. During the TiN deposition, a shutter protected the film from the $\mathrm{Al}$ target discharge. Film thickness was determined by using a crystal quartz transducer.

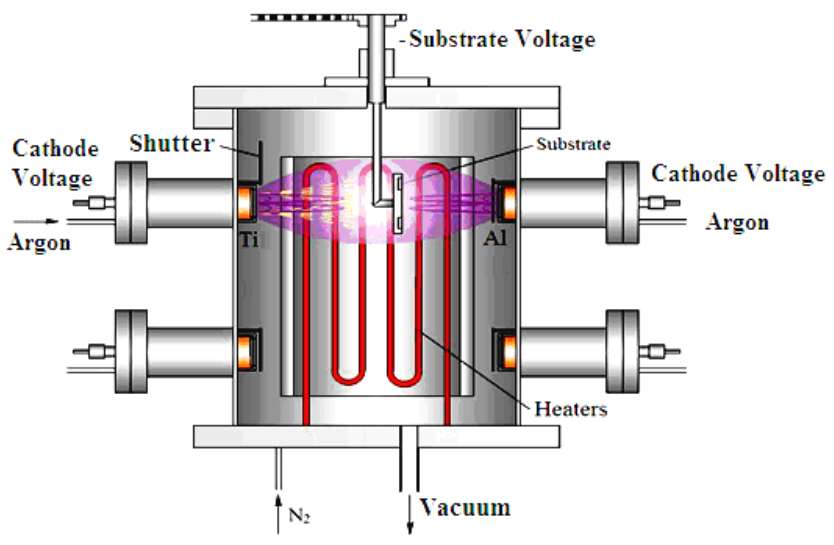

Figure 1. Schematic design of magnetron sputtering for TiN/TiAIN thin film deposition.

The WC insert substrates were coated with TiN/TiAlN multilayers - each with 200 and 300 layers, equivalent to 100 and 150 nanometric bilayers forming thicknesses of 13 and $20 \mathrm{~nm}$, respectively, for a total coating thickness of $4 \mu \mathrm{m}$, as shown in Fig. 2, representing the schematic design of TiN/TiAlN multilayers; this thickness was measured via transversal scanning electron microscopy (SEM) - reported previously (Bejarano et al., 2008).

The morphologic images of flank wear for WC inserts coated with the $[\text { TiN/TiAlN }]_{n}$ multilayer were analyzed by using an optical microscope (Mitutoyo-MF-A1720/H) with amplifications ranging from $10 \mathrm{X}$ to $1000 \mathrm{X}$

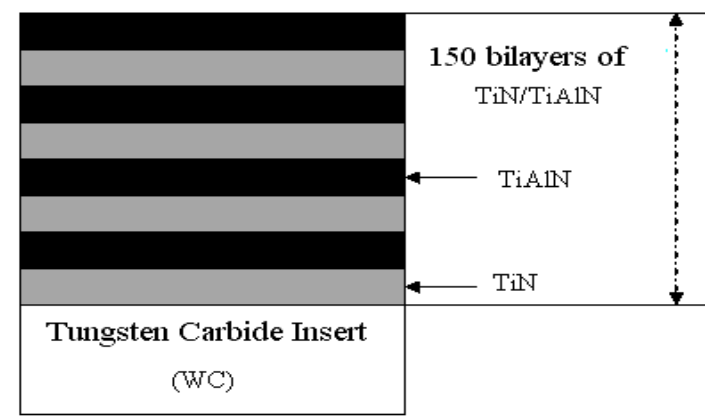

Figure 2. Schematic design of TiN/TiAIN multilayers.

Table 1. Deposition parameter for [TiN/TiAIN]n films.

\begin{tabular}{|l|l|}
\hline Targets & Titanium and Aluminum \\
\hline Deposition System & Reactive r.f. magnetron sputtering \\
\hline Target Power & $300 \mathrm{~W}$ for $\mathrm{Al}$ and $400 \mathrm{~W}$ for Ti \\
\hline Distance Target -substrate & $7 \mathrm{~cm}$ \\
\hline r.f. Bias Voltage & $-100 \mathrm{~V}$ \\
\hline Nitrogen Fluxes & $3.7 \mathrm{sccm}$ \\
\hline Work pressure $\left(\mathrm{N}_{2}+\mathrm{Ar}\right)$ & $6 \times 10^{-3} \mathrm{mbar}$ \\
\hline Substrate temperature & $250^{\circ} \mathrm{C}$ \\
\hline
\end{tabular}

\section{Results and Analysis of TiN/TiAIN Coatings}

The first structural and morphological analysis along with chemical composition and mechanical property analyses of the system used here have been studied and presented prior to this article (Bejarano et al., 2008). The reason for increased and improved mechanical properties like hardness around $42 \mathrm{GPa}$ and elastic modulus around $390 \mathrm{GPa}$ is due to the nature of the multilayer-type structures, because when the number of bilayers is 
increased, micro and nano-hardness is increased; these are individually shown in a previous work by Bejarano et al. (2008). On the other hand, the increased value of critical load supported by our films with the increase in the number of bilayers is due to the increase of adhesion energy, since this is how the multilayers can better absorb the energy applied (Bejarano et al., 2008) (Labdi et al., 1996). This is due to a greater number of TiN and TiAlN intermediate alternating layers with diminishing thicknesses for each monolayer, the energy applied by the load could be absorbed and distributed in greater quantities by the increasing number of bilayers. This is evident when the mechanical development of the coatings is observed, which contemplates the same total thickness with a higher number of [TiN/TiAlN $]_{300}$ multilayers, compared to $[\text { TiN/TiAlN }]_{200}$ multilayers with equal thickness (Labdi et al., 1996).

The design of the nanometric multilayers leads to lower grain sizes, increased interface within the coating, and a blockage of dislocation movement. It also avoids the generation of possible micro and/or nano-fissures due to the number of interfaces between the multilayers (Yang et al., 2002). Multilayered-type hard coatings were obtained with $[\mathrm{TiN} / \mathrm{TiAlN}]_{200}$ and $[\mathrm{TiN} / \mathrm{TiAlN}]_{300}$ heterostructures under the deposition technique used. Hence, the systematic dependence on the increase of the mechanical properties of the films with the increase in the number of bilayers can be analyzed, as stated previously. Films with greater numbers of multilayers almost doubled the performance values.

\section{Materials and Methods for Wear Tests TiN/TiAIN}

Wear tests with both WC inserts coated with TiN/TiAlN were carried out by using AISI 4340 tempered steel samples with 50 HRC hardness. This material is used broadly in high-mechanical performance pieces, especially in the automotive industry. For experimental development, this work used a high-speed cutting (HSC) regime in the cylindrical turning. This technology was applied to diminish machining times and improve surface finish, as well as to permit the elaboration of hardened pieces, even facilitating the development of devices in a single run in the machine.

The values for the parameters used are shown in Table 2. In this work, it was selected the HSC regime and the material of the samples; such as they have been used by different authors, they permit the comparison of wear-behavior results under similar working conditions. For wear measurements of coated WC inserts, an optical microscope with a $0.005 \mathrm{~mm}$ resolution was employed.

Initial tests were conducted on $25 \mathrm{~mm}$ tool displacements to precisely determine the initial wear zone. Upon overcoming this zone, displacement according to the wear behavior of the inserts was increased.

The rejection criteria used for tests stopping is based on wear response (flank wear) because the wear value shows saturation within the experimental error under machining distance for $12 \mathrm{~km}$ in all tests.

Table 2. Values assigned for the parameters in the machining process.

\begin{tabular}{|l|l|l|}
\hline Cutting speed $\left(v_{c}\right)=$ & Feed rate $(d)=$ & Depth of cut $($ doc $)=$ \\
$150 \mathrm{~m} / \mathrm{min}$ & $0.07 \mathrm{~mm} / \mathrm{rev}$. & $0.2 \mathrm{~mm}$ \\
\hline
\end{tabular}

\section{Analysis of Wear Test Results}

In Figure 3, the wear morphology image is evident on the edge of WC insert which is generated by cutting length under $\mathrm{vc}=150 \mathrm{~m} / \mathrm{min}$, $\mathrm{d}=0.07 \mathrm{~mm} / \mathrm{rev}$, and doc $=0.2 \mathrm{~mm}$; where the WC insert coated with $[\text { TiN/TiAlN }]_{\mathrm{n}}$ multilayers $(\mathrm{n}=200$ y 300$)$; but the $[\mathrm{TiN} / \mathrm{TiAlN}]_{300}$ multilayers exhibit highest tribologic contribution, due to show better mechanical properties and TiAlN surface, since these films show high hardness and present low roughness, then adhesive wear is less destructive if compared with other tribological systems, for example, uncoated WC insert. The high hardness and low roughness phenomenon contributes to a reduction of the friction coefficient. Additionally, conferring a superficial hardness that reduces the abrasive wear caused by the interaction between the coated WC insert and machined samples like AISI 4340 steel, which present hardness of 50 HRC (Oxley, 1989). Therefore, the tool life enhancement and the integrity of the cutting WC-insert coated with multilayers can also be shown by optical microscopy analysis with $100 X$.

First, the analysis for [TiN/TiAlN $]_{200}$ coated WC inserts present a cutting length of $11(\mathrm{Km})$ and flank wear $\mathrm{VB}_{\max } 15(\mu \mathrm{m})$. This revealed the behavior shown in Fig. 4. From the results obtained for the WC inserts coated with 200 layers, the results for tests run on WC inserts coated with 300 nano-bilayers are displayed in Fig. 5, These results present cutting length of $11(\mathrm{Km})$ and flank wear of $\mathrm{VB}_{\max } 13(\mu \mathrm{m})$. As noted in Figs. 4 and 5, the curves for both coated WC inserts correspond to the theoretical behavior of cutting tool wear due to saturation for flank wear $\mathrm{VB}_{\max }$, when cutting length exhibits values above $9(\mathrm{Km})$. This behavior corresponds to excessive adhesive wear characteristic for this tribologic system when the coating shows delaminating (Coelho et al., 2007). The analysis for these results (in Figs. 4 and 5) from tests conducted with similar work material and cutting conditions is shown in Table 1.

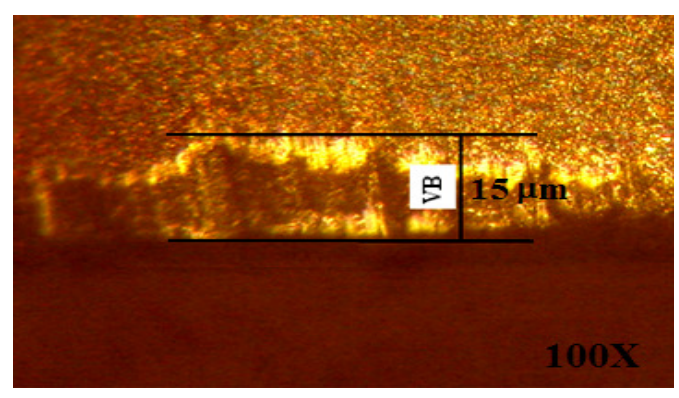

Figure 3. Worn surface of WC tool coated with [TiN/TiAIN $]_{200}$.

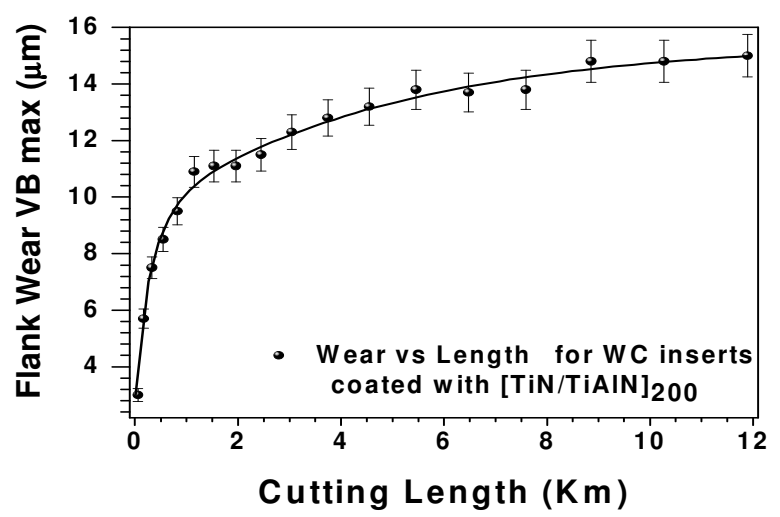

Figure 4. Flank wear for WC inserts coated with 200 nano-layers machined AISI 4340 steel. 


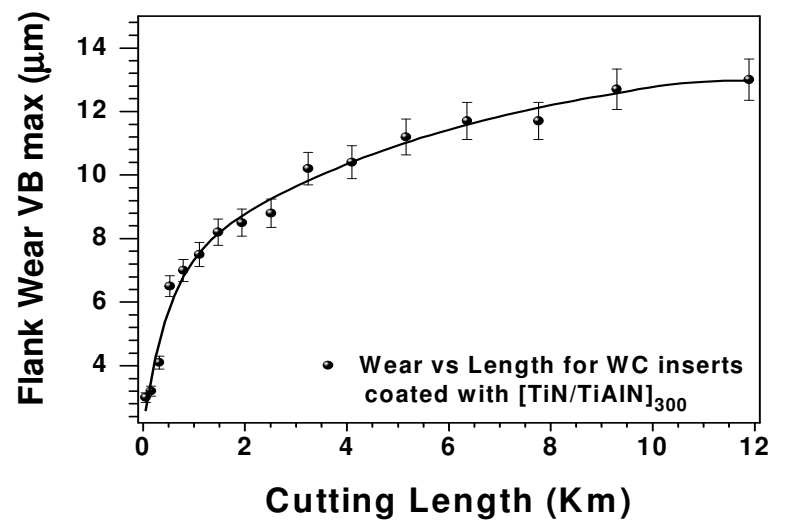

Figure 5. Flank wear for WC inserts coated with 300 nano-layers machined AISI $\mathbf{4 3 4 0}$ steel.

Figure 6 corresponds to measurements made at the NUMA Laboratory (USP-SC), in Brazil, with the same cutting variables, but with $\mathrm{TiCN}-\mathrm{Al}_{2} \mathrm{O}_{3}-\mathrm{TiN}$ coated inserts. The $\mathrm{TiCN}-\mathrm{Al}_{2} \mathrm{O}_{3}$-TiN coating was conducted via deposition method with Sandvik Coromat ${ }^{\circledR}$ monolayers (Coelho et al., 2007). Note that the length traveled by the WC inserts coated with 200 and 300 multilayers of $[\text { TiN/TiAlN }]_{\mathrm{n}}$ shows a 5000 -meter increase of added work. These coatings were made at the Center of Excellence for Novel Materials (CENM) in Cali, Colombia.

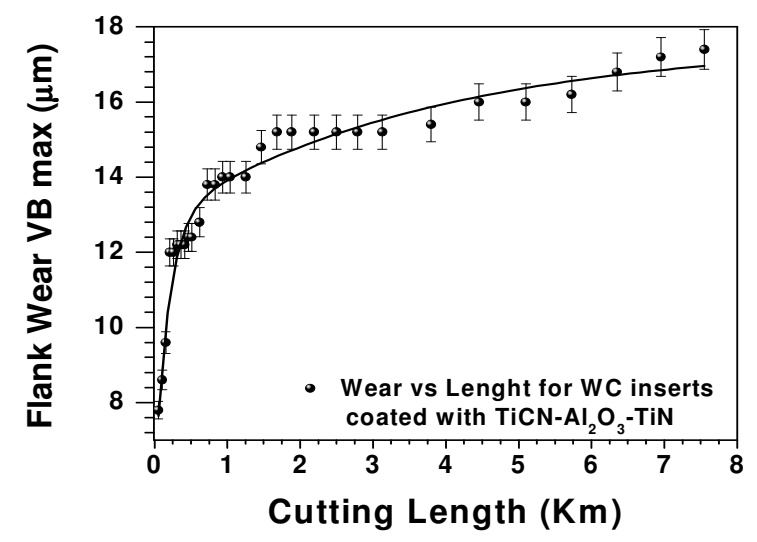

Figure 6. Flank wear for inserts coated with $\mathrm{TiCN}-\mathrm{Al}_{2} \mathrm{O}_{3}-\mathrm{TiN}$ monolayers (Coelho et al., 2007).

Figure 7 shows results obtained by Coelho et al. (2007), where it can be noted that results from inserts with (PCBN-Oxley $\left.{ }^{\circledR}\right)$ substrates and different types of coatings yielded good tool life performance. When comparing the multilayered coated inserts developed at CENM to those coatings with the substrates worked on by Coelho et al. (2007), it is observed that the tool life for both systems is similar when analyzing a value of $11(\mathrm{Km})$ for cutting length; although the latter is more expensive than the WC insert coated with our multinanolayers. For the PCBN inserts tested with different coatings like monolayered and nanostructured coatings, nano-scaled TiAlN is the coating that withstands the highest working temperature - around $900{ }^{\circ} \mathrm{C}$ (Endrino and Derflinger, 2005). In other words, the function of aluminum and titanium nitride provides a high-hardness coating with high-oxidation temperature (Endrino and Derflinger, 2005).

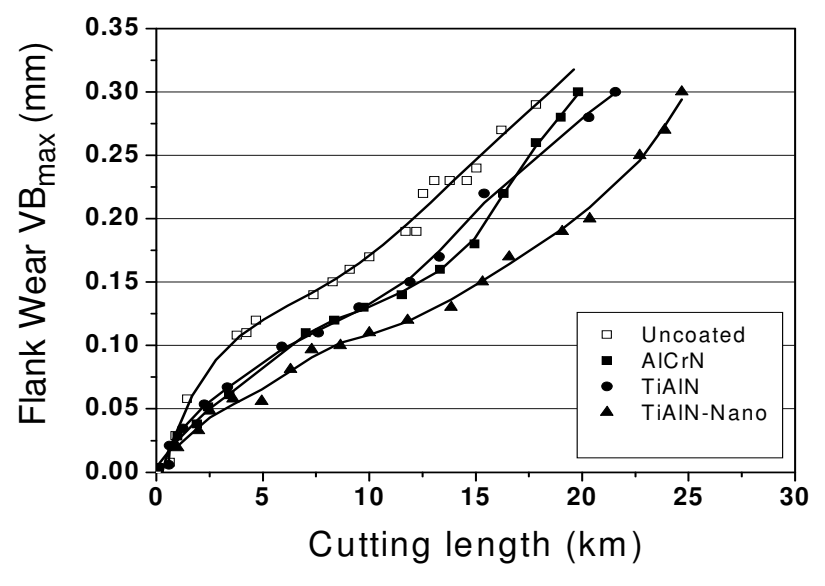

Figure 7. Flank wear as a function of cutting length. Machined with $v_{c}=$ $150 \mathrm{~m} / \mathrm{min}, f=0.07 \mathrm{~mm} / \mathrm{rev}$, and $h=0.2 \mathrm{~mm}$ (Coelho et al., 2007).

\section{Conclusions}

In this work, the WC inserts coated with $[\mathrm{TiN} / \mathrm{TiAlN}]_{300}$ nanostructured multilayers revealed higher tool life values than the WC inserts coated with 200 monolayers corresponding to lowest flank wear. The $[\mathrm{TiN} / \mathrm{TiAlN}]_{300}$ multilayers show a $13 \%$ lower flank wear than $[\mathrm{TiN} / \mathrm{TiAlN}]_{200}$. This behavior is in relation to high hardness and low roughness present for $[\mathrm{TiN} / \mathrm{TiAlN}]_{300}$ multilayers.

The comparison of $[\mathrm{TiN} / \mathrm{TiAlN}]_{\mathrm{n}}$ nanostructured multilayers with results from other authors, including PCBN-coated WC inserts, reveals that the nanostructured multilayers have better mechanical behavior, because the adhesive wear is less destructive if compared to other tribological systems, for example the $[\mathrm{TiN} / \mathrm{TiAlN}]_{300}$. They exhibit a 33\% lower flank wear than WC inserts coated with TiCN$\mathrm{Al}_{2} \mathrm{O}_{3}$-TiN monolayers and, moreover, the $[\mathrm{TiN} / \mathrm{TiAlN}]_{300}$ nanostructured multilayers are less expensive than the PCBN-coated ones.

Finally, the experimental development and technology used at CENM, via magnetron sputtering growth, is adequate and permits studying different deposition parameters to reach optimal deposition values. Therefore, the method correlation with measured wear demonstrated results based on optical microscopy, corresponding to experimental wear curves in cutting tools and permitted comparison with other results shown in the literature. Hence, this method is appropriate for the evaluations conducted. Furthermore, tests for physical, mechanical, and structural characterization of the coated WC inserts used in the tests reveal that such have appropriate parameter values.

\section{Acknowledgements}

This work was supported by the Center of Excellence for Novel Materials - CENM, through the CDT-ASTIN, SENA and the Thin Film Group at Universidad del Valle in Cali, Colombia, along with collaboration from the Grupo de Materiales del Departamento de Tecnología - Facultad de Ingeniería Mecánica of Inst. Sup. Politécnico José Antonio Echeverría in Cuba.

\section{References}

Bejarano, G. et al., 2008. "Mechanical and tribological properties enhancement of heat treated AISI 4340 steel by using a TiN/TiAlN multilayer coating system”. Rev. Fac. Ing. Univ. Antioquia. Vol. 44, pp. 36-42.

Braic, M. et al., 2003, "Plasma deposition of alternate TiN/ZrN multilayer hard boatings", Journal of Optoelectronics and Advanced Materials Vol. 5, No. 5, pp. 1399-1404. 
Coelho, R.T. et al., 2007, "Tool wear when turning hardened AISI 4340 with coated PCBN tools using finishing cutting conditions", Journal of Machine Tools \& Manufacture. Vol. 47, pp. 263-272.

Endrino, J.L. and Derflinger, V., 2005, "The influence of alloying elements on the phase stability and mechanical properties of $\mathrm{AlCrN}$ coatings". Surface and Coatings Technology. Vol. 200, pp. 988-992.

Guo, Y.B and Janowski, G.M., 2004 "Microstructural characterization of white layers formed during hard turning and grinding", Transactions of NAMRI/SME. Vol. 32, pp. 367-374.

Holleck, H., 1986, "Material selection for hard coatings", J. Vac. Sci. Technol., Vol. 4, pp. 2661-2666.

Komanduri, R., Chandrasekaran, N. and Raff, L.M., 2001, "Molecular dynamics simulation of the nanometric cutting of silicon", Phil. Mag. B, Vol. 81, pp. 1989-2019.
Labdi, S. et al., 1996, "Elaboration and characterization of Ti and TiN thin films and Ti/TiN multilayers for hard coating applications", Thin Solid Films. Vol. 275, pp. 213-215.

Musil, J., 2000, "Hard and superhard nanocomposite coatings", Surf. Coat. Technol. Vol. 125, pp. 322-327.

Oxley, P.L.B., 1989, "The Mechanics of Machining: An Analytical Approach to Assessing Machinability", Ellis Horwood, Chichester, England.

Shaw, M.C., 1984, "Mechanics of Orthogonal Cutting, Metal Cutting Principles", Oxford University Press, London.

Usui, E., 1998, "Progress of predictive theories in metal cutting", JSME Int. J., Ser III. Vol. 31(2), pp. 363-369.

Yang, Q. et al., 2002, "Preferred orientation and hardness enhancement of TiN/CrN superlattice coatings deposited by reactive magnetron sputtering”, Scripta Materialia. Vol. 46, pp. 293-299. 